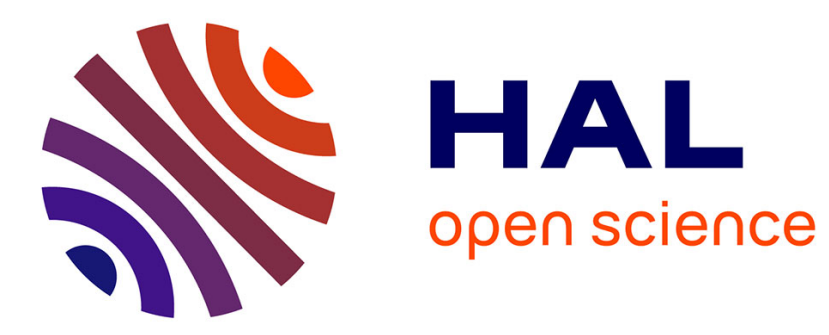

\title{
Influence of gravity on the skin thermal behavior: experimental study using dynamic infrared thermography
}

\author{
Domoina Ratovoson, Franck Jourdan, Vincent Huon
}

\section{To cite this version:}

Domoina Ratovoson, Franck Jourdan, Vincent Huon. Influence of gravity on the skin thermal behavior: experimental study using dynamic infrared thermography. Skin Research and Technology, 2013, 19 (1), pp.397-408. 10.1111/j.1600-0846.2012.00657.x . hal-00786969

\section{HAL Id: hal-00786969 \\ https://hal.science/hal-00786969}

Submitted on 11 Feb 2013

HAL is a multi-disciplinary open access archive for the deposit and dissemination of scientific research documents, whether they are published or not. The documents may come from teaching and research institutions in France or abroad, or from public or private research centers.
L'archive ouverte pluridisciplinaire HAL, est destinée au dépôt et à la diffusion de documents scientifiques de niveau recherche, publiés ou non, émanant des établissements d'enseignement et de recherche français ou étrangers, des laboratoires publics ou privés. 


\title{
Influence of gravity on the skin thermal behavior: experimental study using infrared thermography
}

\author{
Domoina Ratovoson, Franck Jourdan, Vincent Huon \\ Laboratory of Mechanics and Civil Engineering \\ CNRS, University Montpellier 2
}

France

\begin{abstract}
In order to better understand the thermomechanical behavior of the skin and its direct environment, we present an experimental study using infrared thermography. This experimental study aims to highlight quantitatively some effects of blood flow on the heat diffusion. The originality of this research is to change the blood flow by using effects of gravity and to quantify the temperature changes. The experimental step consists to put a cylindrical steel bar cooled or warmed on the skin of a human forearm and to measure the change of the temperature using an infrared camera. Measures have been recorded for different positions of the forearm. We noted very clearly the influence of blood circulation in the veins on the diffusion of the temperature. The return to thermal balance is faster when the arm is in a horizontal position. More over, a comparative study of experimental cooling and warming showed a symmetrical thermal behavior for the skin under this type of thermal solicitations. This work provided to build a database which can be used for the validation of predictive thermal models of human skin.
\end{abstract}

${ }^{*}$ Corresponding author: Address: Laboratoire de Mécanique et Génie Civil, CC48, Université de Montpellier 2, Place Eugène Bataillon, 34095 Montpellier, France; phone: 33467149633; fax: 33467143923; email:jourdan@lmgc. univ-montp2.fr 
Keywords: Thermomechanics, Skin, Blood flow, Infrared thermography, Heat transfer.

\section{Introduction}

The skin is a protective covering of the body and a complex organ that contains several mechanisms for fully functioning human body. With its strength, elasticity and cohesion of the whole structure, it protects the body against mechanical shocks. It also helps to maintain constant temperature of our body. Against the cold, the body increases its metabolism. This leads to a decrease in energy reserves Against the hot, active dilation of small vessels of the dermis promotes the removal of excess heat.

Since the beginning of $19^{\text {th }}$ century, several researchers have attempted to characterize the skin in vitro and in vivo. Studies in vitro revealed complex mechanical behavior linked to the multilayer structure of the skin. Unfortunately, they do not describe the natural functioning of the skin as it works only in a living body (see (1)).

From 40 years, several research groups have studied the thermomechanical characterization of the skin in vivo. They noticed that blood flow plays an important role in heat distribution. With modern experimental techniques (Laser Doppler $(2 ; 3 ; 4 ; 5)$, infrared imaging techniques $(6 ; 7 ; 8 ; 9 ; 5))$, observations became more precises. Infrared imaging or thermography is a method for acquisition of infrared radiation associated with the spatial distribution of heat on the objects examined, and the variation of this distribution over time.

In our study, but also in $(12 ; 13 ; 14)$ thermography measures the temperature related to the cutaneous microcirculation and macro subcutaneous blood flow. 
Our experimental study aims to highlight quantitatively some effects of blood flow on the heat diffusion. The originality of this research is to change the blood flow by using effects of gravity, to quantify the temperature changes. This work comes to supplement a preceding study (10) conducted on the same topic.

For that, we carried out a campaign of experimentation. The method was to use infrared measurements on a skin of a human forearm to identify changes in temperature and the influence of the veins in the tissue. This article is divided into four sections. At first, we present the experimental device. We will see the experimental protocol and the various stages of action. In a second step, we discuss on experimental data. We will present the evolution of temperature with respect to time and an analysis of them. Then we will see, the comparative study of experimental cooling and warming. Finally, are described, discussions and feedback of results.

\section{Materials and methods}

\section{$2.1 \quad$ Experimental protocol}

The experimental study was carried out using infrared thermography. The campaign of experimentation informed us about the evolution of the temperature in vivo of the skin on the human forearm. To impose a temperature variation, we used twelve cylindrical steel bars. Six of them were put in the refrigerator at $10^{\circ} \mathrm{C}$ while the remaining six were put in an oven 
at $42^{\circ} \mathrm{C}$. They stayed for two hours.

Each cylindrical cooled or heated bar was placed on the forearm for 20 seconds and then removed. Then, the recording of the thermal image was performed during 90 seconds.

We treated three positions of the forearm: a horizontal position, an upward vertical position (see figure 1) and a downward vertical position (see figure 2). The forearm has been immobilized to obtain usable results. The time interval between two consecutive measures was about 7 minutes. An infrared image was taken before to check that thermal balance had been recovered. Surface temperatures were measured at the same location on the forearm. This location was marked with a circle drawn in pen on the skin. We identified a reference point. For this, an adhesive tape of squared form of size $(2 \times 2) \mathrm{cm}^{2}$ were sticked on the skin. It was located about $4 \mathrm{~cm}$ from the center of the location of the bar. This is one of the vertices of the square that served as a reference point (see figure 2). Once everything were in place, we put the arm in position. For analysis, we identified the part where there was a passage of a vein. Indeed, it was expected a more rapidly warm in this area.

During experimentations the temperature of the experimental room was controlled. The camera was located approximately $50 \mathrm{~cm}$ from the measuring points. Measures were concentrated on a surface of $(10 \mathrm{x} 4) \mathrm{cm}^{2}$.

\subsection{Characteristics of the infrared camera}

Our research team has been working for many years on the characterization of material. Infrared thermography is an experimental technique that we control relatively well, allowing 

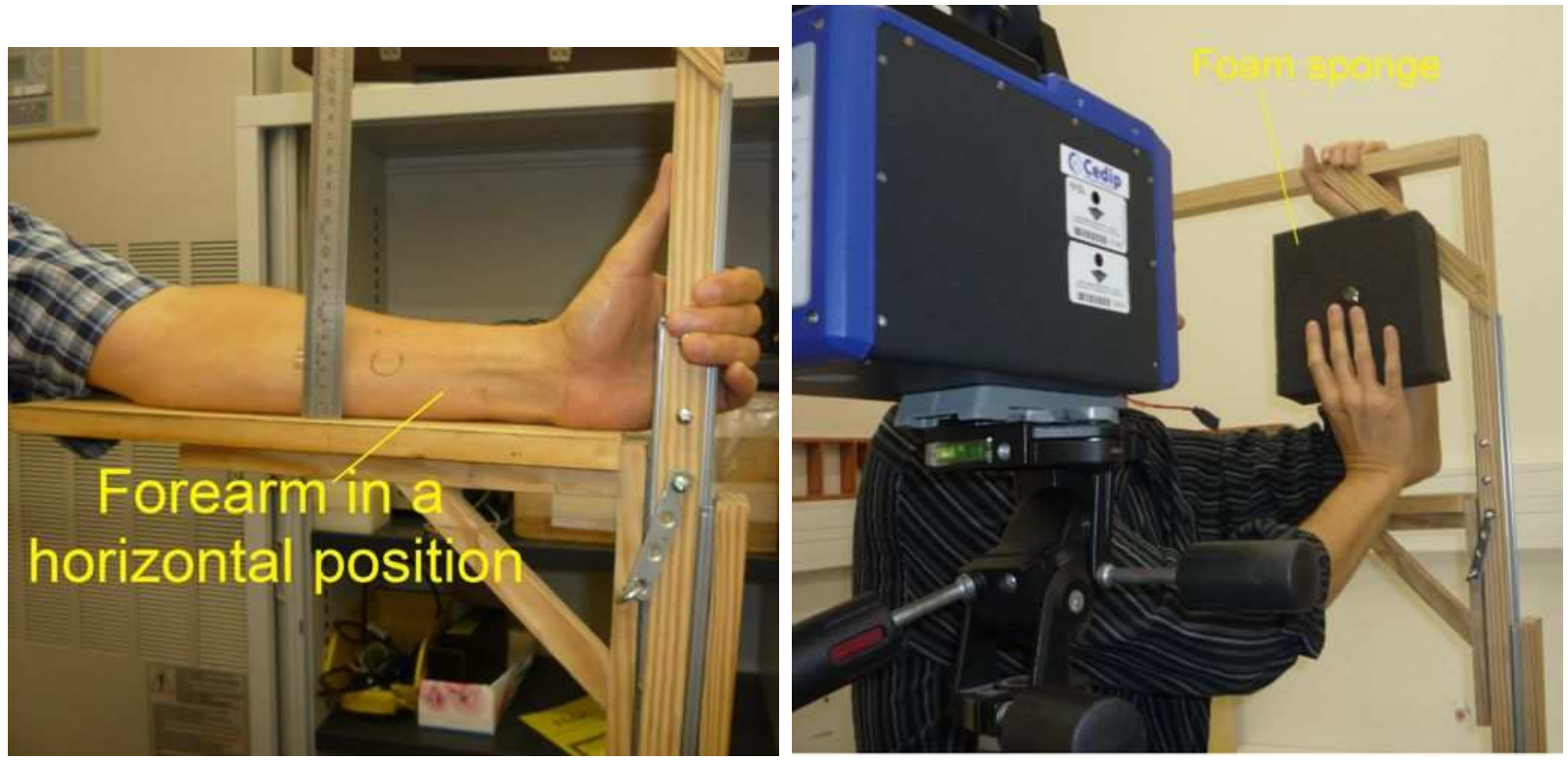

Figure 1: Forearm in a horizontal position (left) and upward vertical position (right)

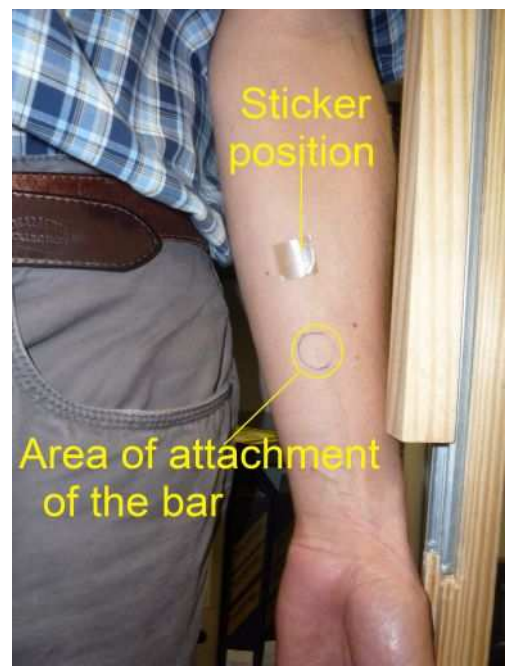

Figure 2: Sticker on the forearm as a reference frame and zone of contact for the bar for the downward vertical position

us to accurately balance energy (15). Infrared cameras have greatly evolved over the past thirty years. The first single-detector cameras operated with a scanning system to cover the observed surface (11). Today modern infra-red digital cameras employ focal-plane array 
technology. Our experimental setup included a focal plane array infrared camera (IRFPA Cedip 560 Titanium). The maximum frame-rate of the IR camera was 100 images per second, with each image consisting of 512 x 640 pixels, each pixel has a size of $30 \mu \mathrm{m} \times 30 \mu \mathrm{m}$. The signal is then amplified and digitized at 14 bits or 16,384 levels computing. The sensor operates in a medium wave band equal to 3-5 $\mu \mathrm{m}$. We used an IR measurement protocol based on an individual calibration of detector elements $(16 ; 17)$. This is an individual pixel calibration based on polynomial fitting of the temperature as a function of the signal $s_{i}$ delivered by the $\mathrm{i}^{\text {th }}$ element of the detector when the camera is placed in front of the black body source at different temperatures. The infrared camera used has an objective of focal length $50 \mathrm{~mm}$ and a spatial resolution of $0.15 \mathrm{~mm} /$ pixel.

\subsection{Other tools Required}

We used cylindrical steel bars of length $10 \mathrm{~cm}$ and $2 \mathrm{~cm}$ in diameter. We used a wooden structure to support and secure the forearm during installation of the bar and the recording of the thermal image.

We also used a foam sponge with the dimensions $(20 \mathrm{x} 20) \mathrm{cm}^{2}$ and a thickness of $6 \mathrm{~cm}$, to isolate the bar when handling (see figure 1).

\section{$3 \quad$ Experimental results}

In this paragraph, we present experimental results obtained using infrared thermography. Measurements have been carried out on a male 41 years old, for different forearm positions. 
More experimental results obtained on a female subject are presented in appendix A and B. Figure 3 gives a representation of the evolution of the temperature during the experiment in the horizontal position. The recording was made after the removal of the cooled cylindrical bar. The air temperature during the experiment was $21^{\circ} \mathrm{C}$. The first image corresponds to $\mathrm{t}=0 \mathrm{~s}$ after removal of the cooled cylindrical bar. This image shows the beginning of the thermal recording. The contact area could be identified in the center of the image. The second image corresponds to $t=30 \mathrm{~s}$. We clearly see the influence of the vein that transports heat. Image 3 was taken at $\mathrm{t}=60 \mathrm{~s}$ and image 4 , taken at $\mathrm{t}=90 \mathrm{~s}$, corresponds to the end of the recording.
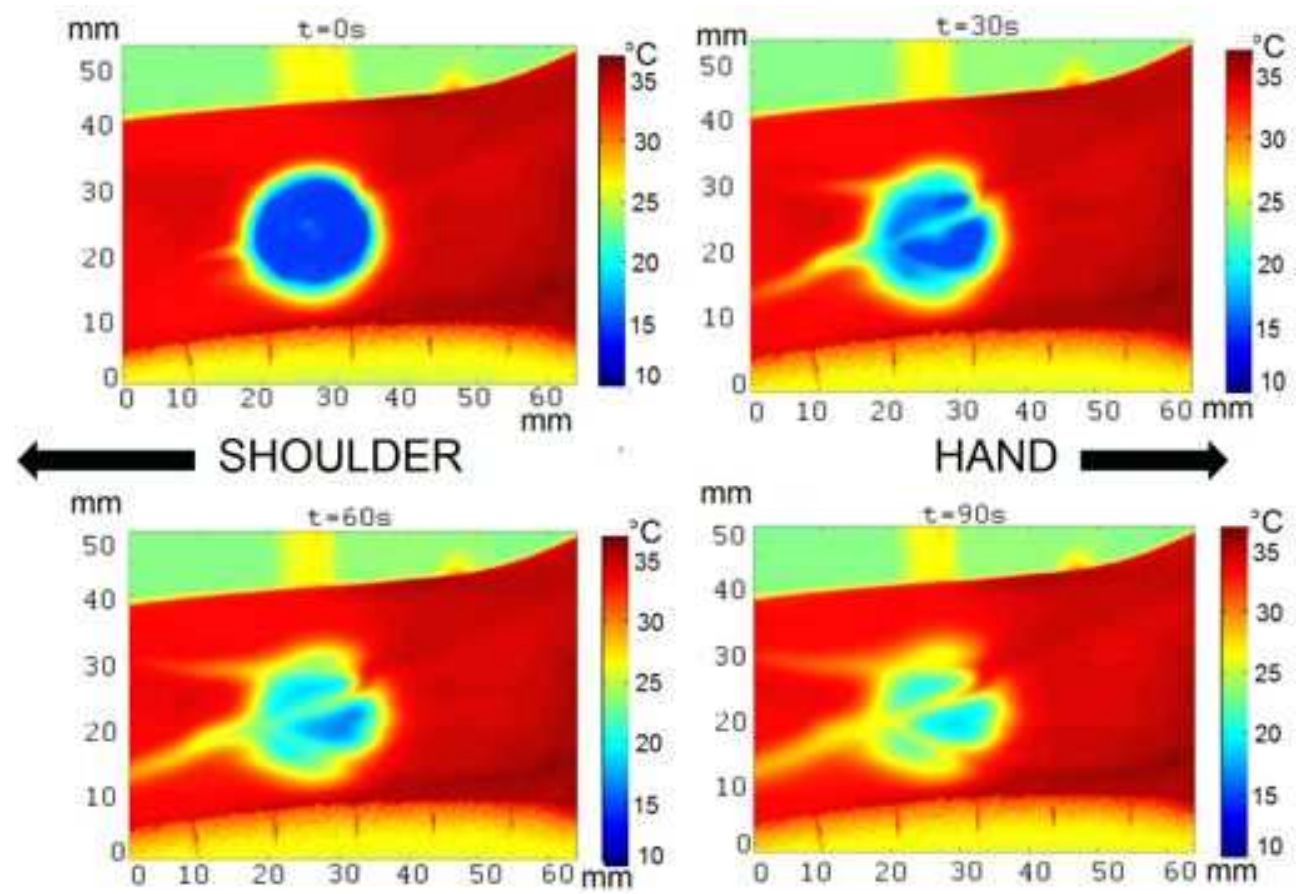

Figure 3: Evolution of temperature on the forearm after cooling, from the beginning (top-left image) to the end of measurement (bottom-right image). Temperatures are in ${ }^{\circ} \mathrm{C}$.

The following results was recorded for the three positions with cooled and heated bars. 


\subsection{Comparison of results between horizontal and upward vertical positions with bars cooled and heated}

We selected seven points on the images of figure 4 for both cooled and heated bars. Points 3, 4 and 5 are located in the area of application of the cylindrical bar and points 1,2,6 and 7 are outside the contact area. Points 2, 4, 6 and 7 are on the passage of a vein.

To compare the results of the horizontal and upward vertical positions, the same check points (see figure 5) was chosen. The blue dashed curves are those of the horizontal position and the red continuous curves are those of the upward vertical one.

Points 6 and 7 were located on the passage of a vein. Their temperature dropped and returned to thermal balance. This shows the influence of venous blood in heat diffusion. In the first moments the blood is cooled and lowers the temperature of downstream tissues. Points 3 and 5 were located under the cooled zone with no vein passage. Their temperature increased until thermal balance, like it would increase for inert materials. Point 4 was under the cooled zone and on the passage of a vein. Its curve was shaped like those of points 3 and 5 but with a higher initial temperature and a faster return to thermal balance. Point 1 was outside the cylinder. There was little temperature variation.

For the upward vertical position, observations are exactly the same as in the horizontal position. 
However, looking at points 3,4 and 5 in the horizontal position, the return to thermal balance is faster.
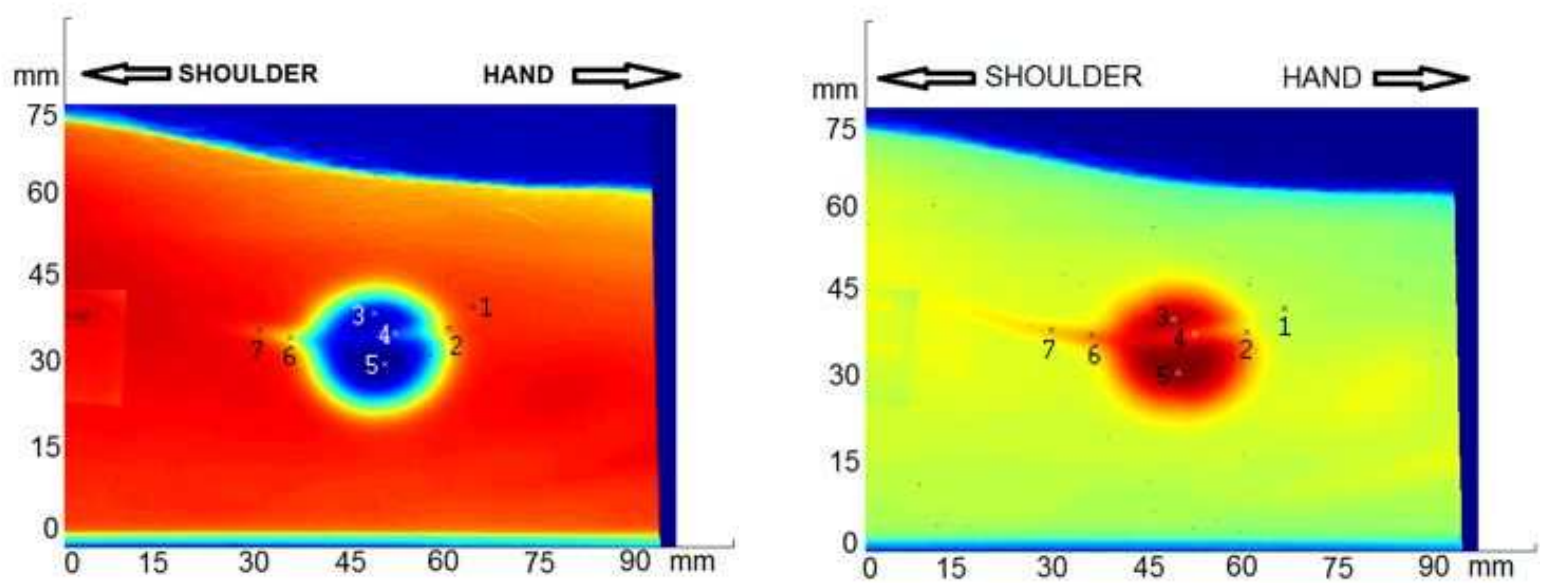

Figure 4: Thermal image of the forearm in the horizontal position: male subject - cooled bar (left) and heated bar (right).

\subsection{Comparison of results between horizontal and downward verti- cal positions with bars cooled and heated}

Figure 6 shows the comparison of results between horizontal and downward vertical positions with bars cooled and heated for the male subject. The blue dashed curves are those of the horizontal position and the black continuous curves are those of the downward vertical one. Relative to the horizontal position, the warming is slower too in the downward vertical position. 

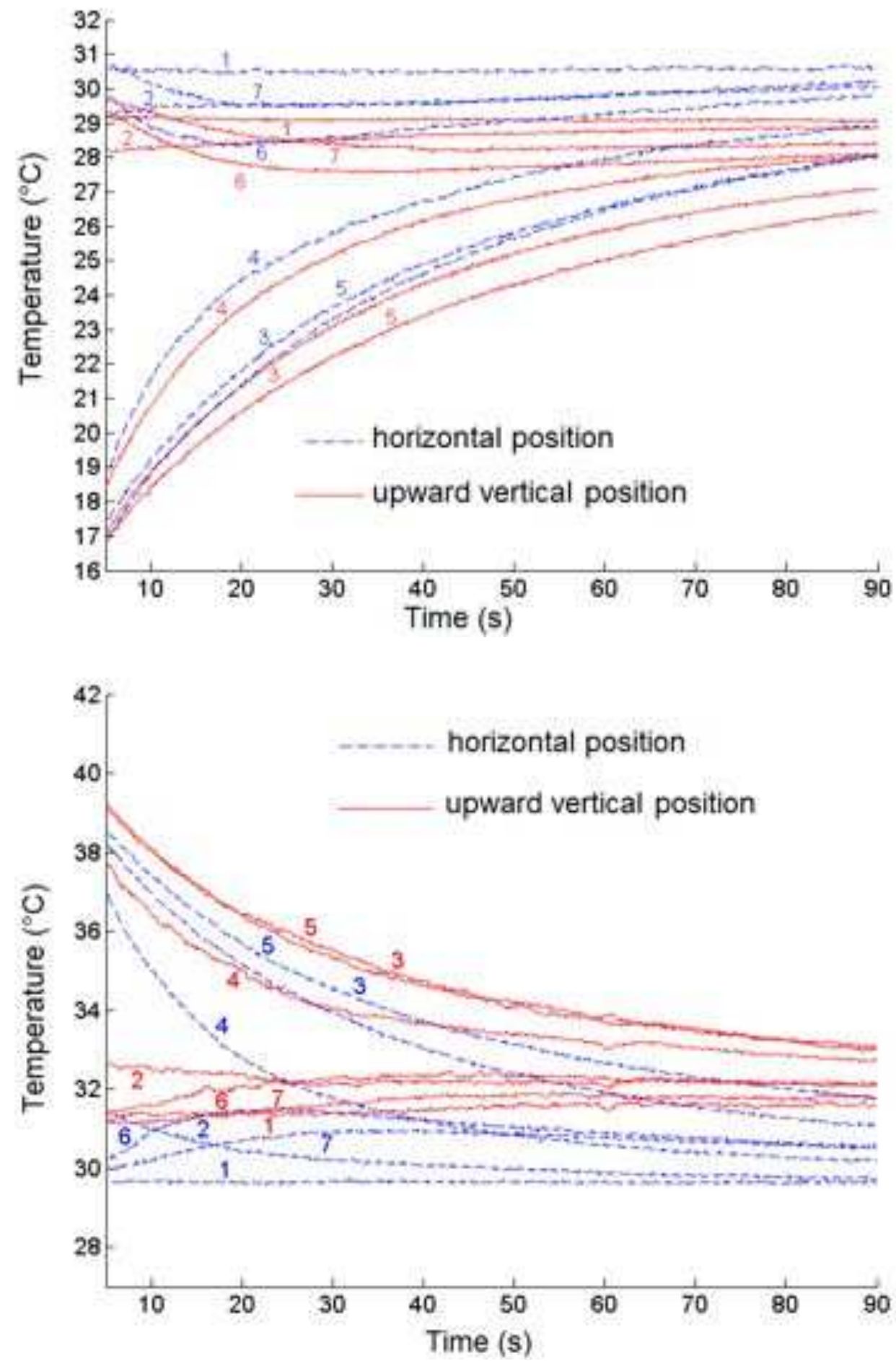

Figure 5: Comparison of check points temperature evolution between horizontal and upward vertical positions: male subject - cooled bar (top) and heated bar (bottom). 

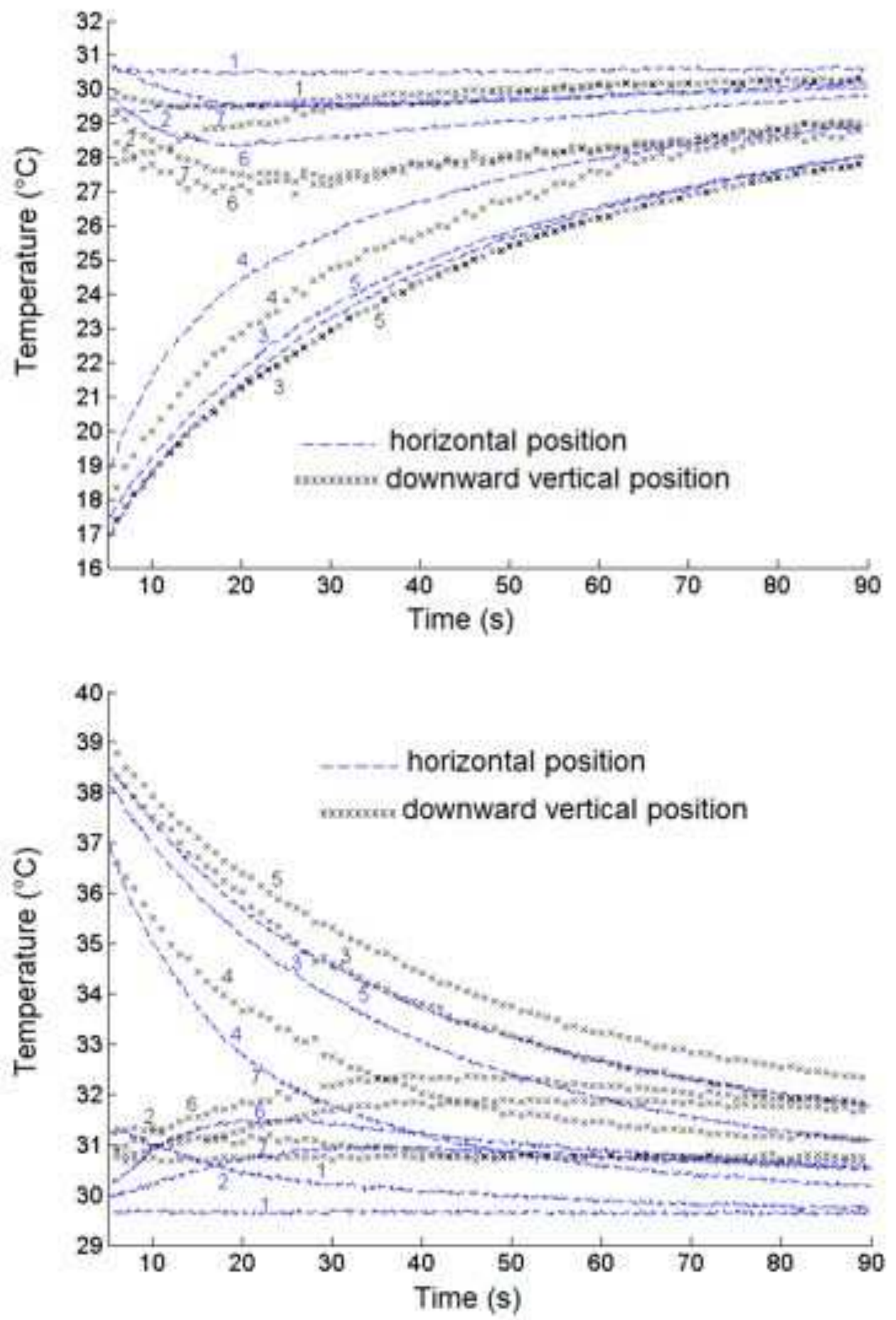

Figure 6: Comparison of results between horizontal and downward vertical positions: male subject - bar cooled (top) and heated bar (bottom). 


\subsection{Comparison of results between vertical positions with bars cooled and heated}

Figure 7 shows the comparison of experimental results between the two vertical positions upward and downward, with bars cooled and heated for the male subject. The warming is slower for the upward vertical position.

\subsection{Comparative study between cooling and warming}

This kind of comparisons does not make sense for inert materials. Indeed, one expects a symmetry of the thermal behavior. But, for alive materials, it is not obvious. It is well known that the adaptation of living tissues depends on thermal solicitations. Against the cold, the body increases its metabolism. Against the hot, active dilation of small vessels of the dermis promotes the removal of excess heat.

This section presents a comparative study between cooling and warming of the skin for the male subject. Comparative results for the female subject are gathered in appendix B. First results concern the horizontal position. Selected check points are number 3,4 and 6 (see image on the top of figure 8). In the graphic at bottom of figure 8 are plotted the temperature evolutions of check points for both cooled and warmed bars. We observe a symmetry of the thermal behavior.

A same symmetrical thermal behavior is found for the vertical positions (see figures 9 

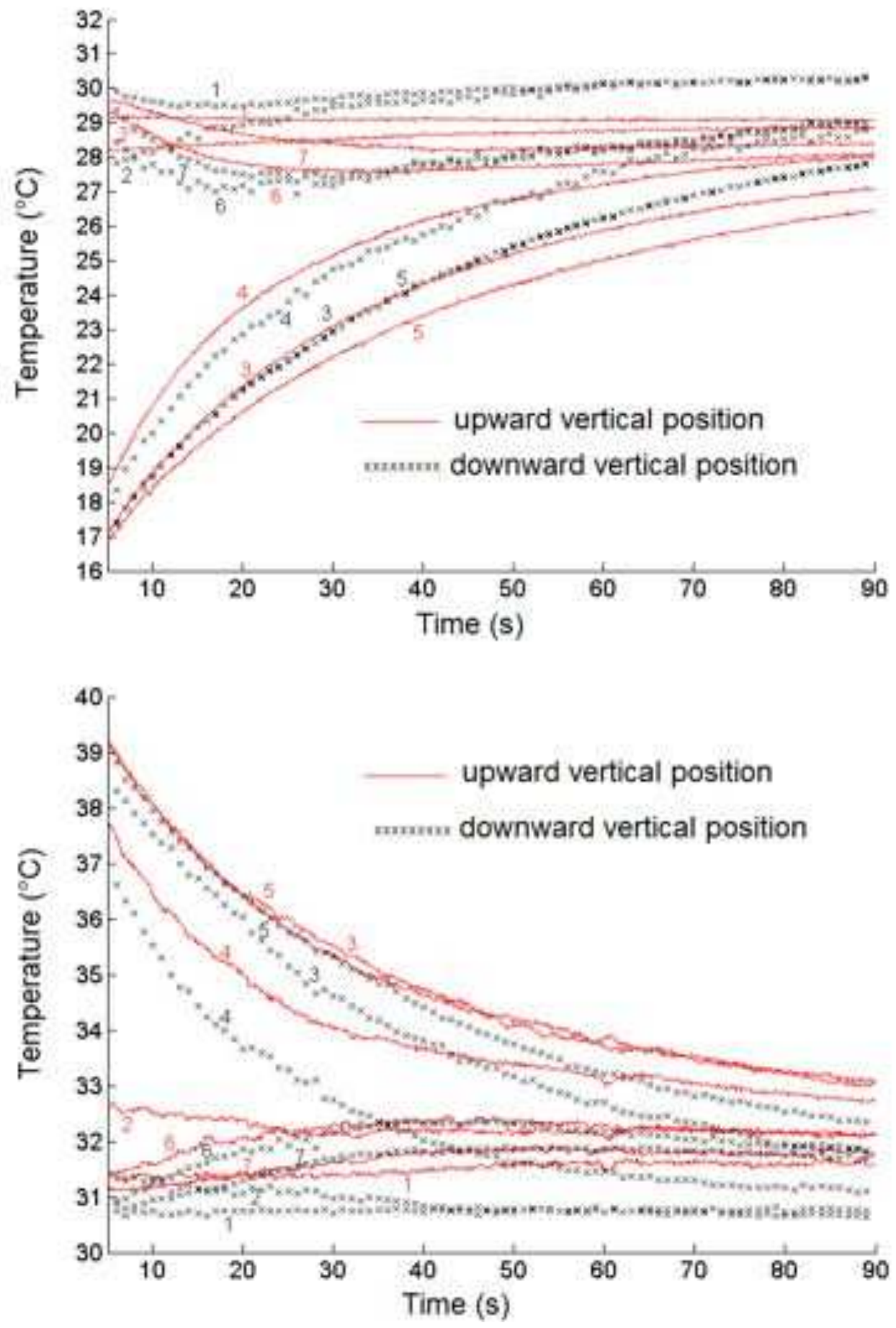

Figure 7: Comparison of results for the upward and downward vertical positions: male subject - bar cooled (top) and heated bar (bottom). 


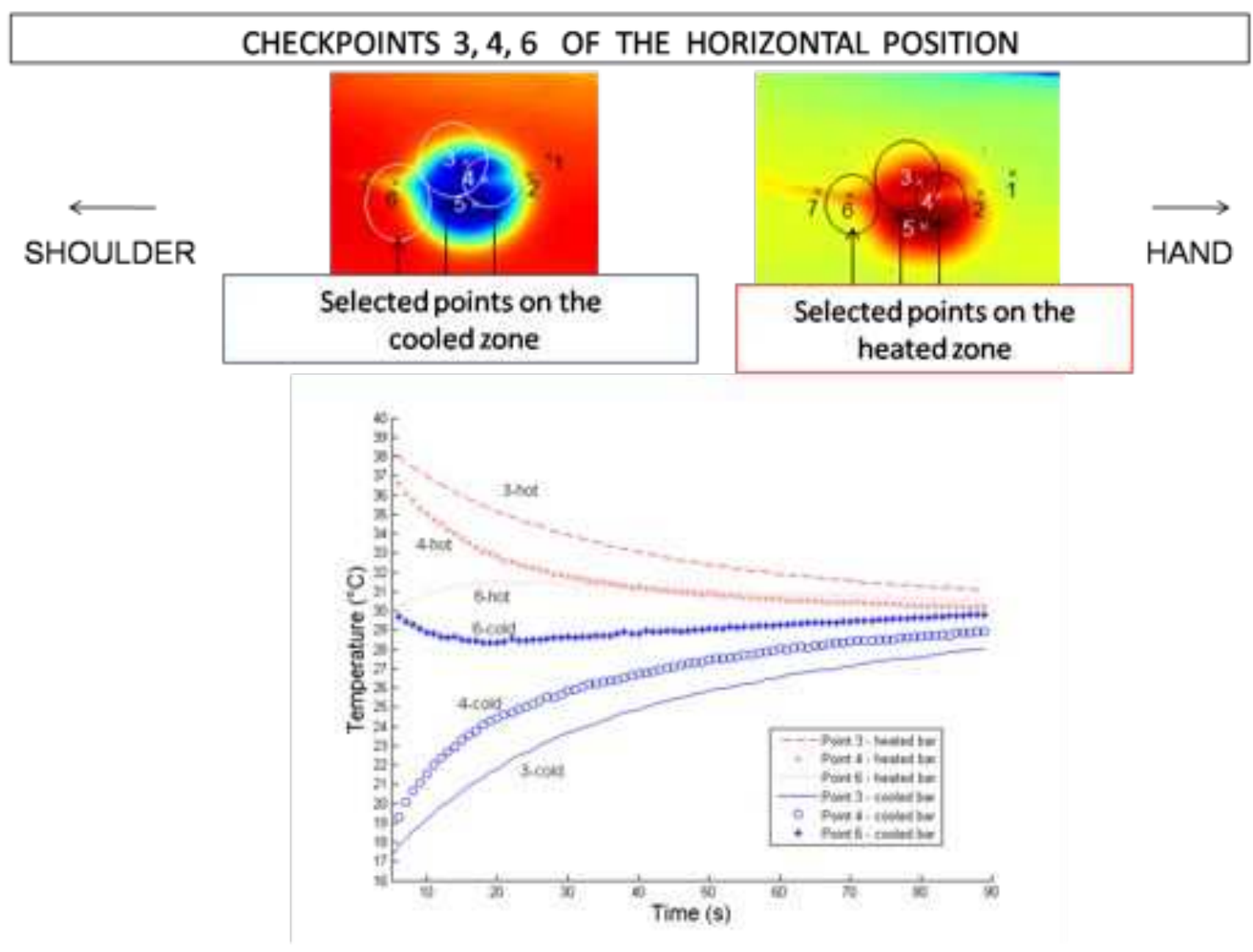

Figure 8: Comparisons between cooling and warming in the horizontal position for check points 3,4 and 6

and 10)

\section{Comments and discussion}

This measurement campaign has highlighted the influence of blood flow on the thermal regulation of the skin. There are several phenomena:

- On the heat transport through the veins: the temperature measured at points 2, 6 and 7, located on a passage of a vein, showed variations associated to heat transport. We 


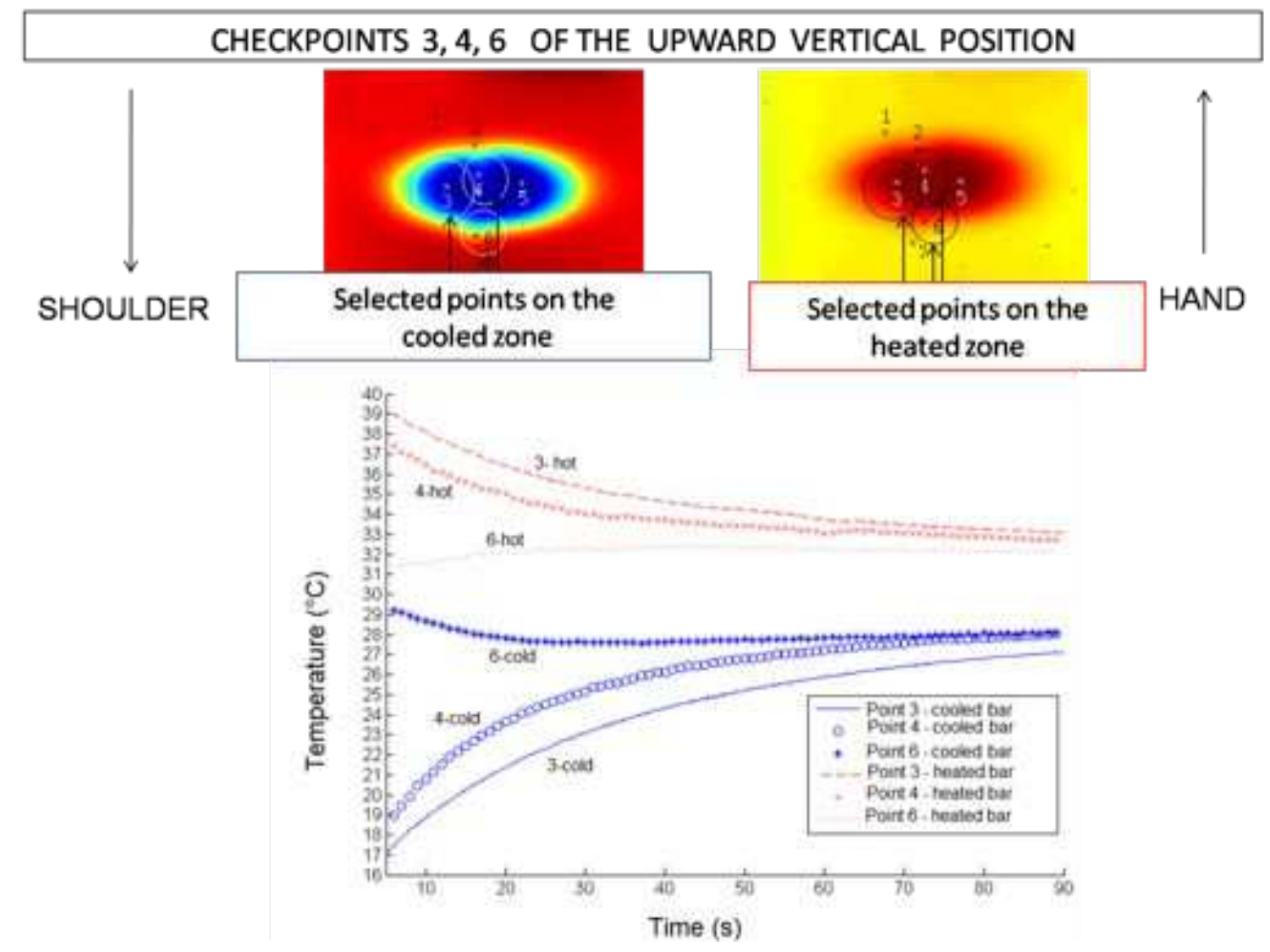

Figure 9: Comparisons between cooling and warming in the upward vertical position for check points 3,4 and 6

observed a drop followed by a fast rise in the temperature of tissue downstream from the cooled zone.

- The method of varying the blood flow by changing the position of the forearm, can show that the return to thermal balance is faster in the horizontal position. It is faster than in the downward vertical position which is faster than in the upward vertical one. This difference may be accounted for by the fact that perfusion and blood circulation were less important in the vertical position than in the horizontal position. Blood has 


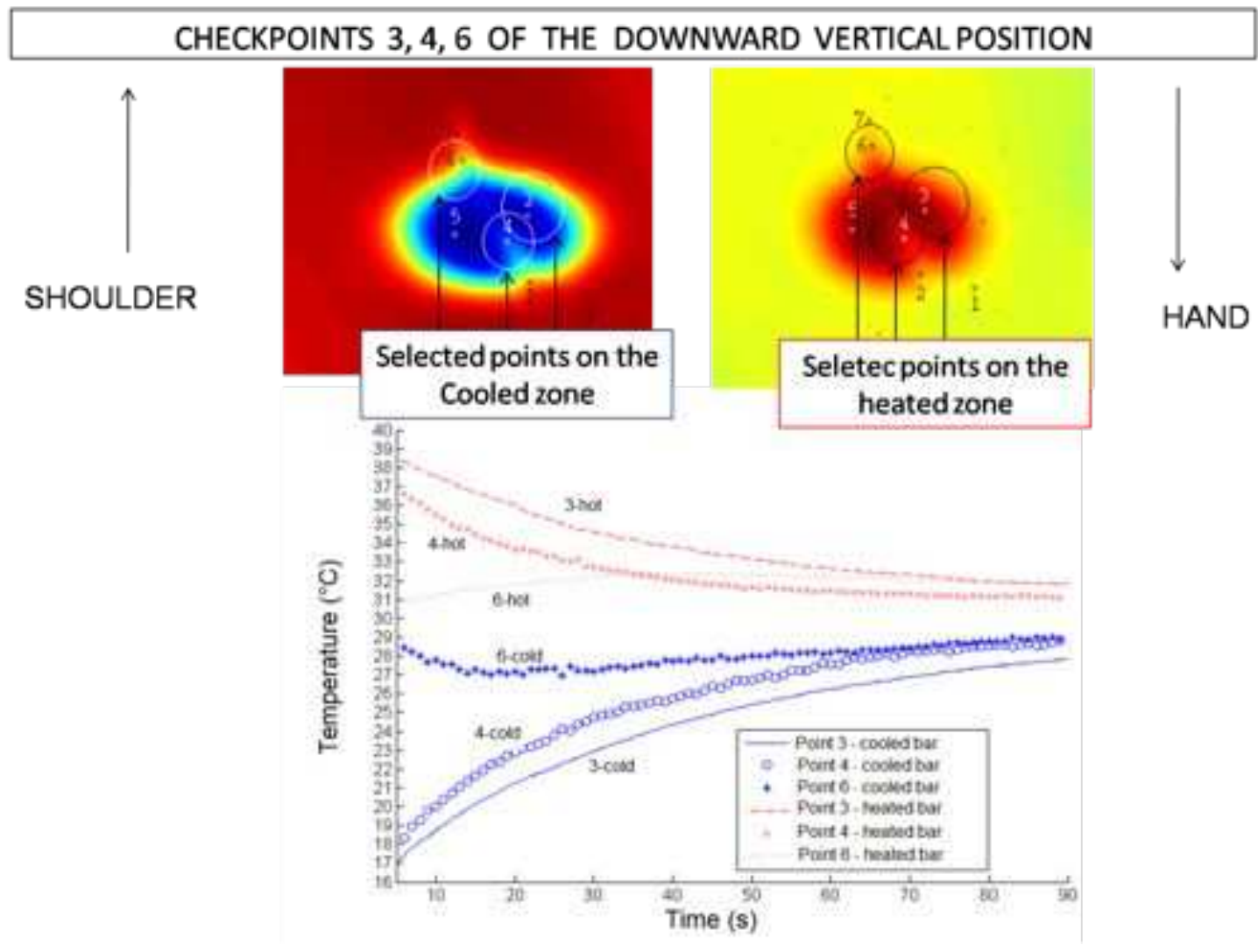

Figure 10: Comparisons between cooling and warming in the downward vertical position for check points 3,4 and 6

more difficulty circulating in the vertical position than in the horizontal position.

- The thermomechanical behavior of the skin is verified in both the warming and cooling phase.

- Other measures to a female 30 years old have been done and are gathered in appendix A. Two other human subjects (one male and one female) have been tested. Experimental results could be found in (18). Same comments and conclusions on thermal behavior can be done. 
- The comparative study of cooling and warming shows that there is a symmetry of the thermomechanical behavior of the organ. This is also observed for the women subject (see appendix B). This symmetry is checked only for this kind of thermal solicitations and for a temperature variation that do not damage the skin. It is obvious that this symmetrical behavior should not be checked any more when the temperature variations increase.

Note also that the experimental protocol, we have implemented, allows a fairly good reproducibility of results. We got to get initial temperatures in the contact area with less than one degree deviation between the 3 forearm positions.

\section{Conclusion}

We developed an experimental protocol using infrared thermography to quantify heat transfers in the human skin. The experimental approach was to put a cylindrical steel rod previously cooled or heated on the skin of a human forearm and measure the change in temperature with an infrared camera. Experimentally, we found a clear influence of blood flow in the veins on the distribution of temperature in different positions of the forearm. The purpose of this study was to vary the blood flow by using effects of gravity. This approach allowed us to quantify the temperature changes due to those blood flow modifications.

We found, based on experimental data, the effects of perfusion and blood flow were smaller in the vertical positions with respect to the horizontal position. This finding comes from the observation of the delay to join thermal balance for check points located on the surface 
of the forearm. It was observed that the return to thermal balance in the vertical positions was slower.

We performed a comparative study of experimental cooling and warming in male and female subjects. We found a symmetrical behavior for this kind of thermal solicitations.

We encountered some difficulties, particularly in terms of approach and experimental protocol. The arm must be motionless to get usable results from the thermal recording. The initial temperatures of the cylindrical bars used must be relatively close for the different positions. In addition, the heat transfer between the bar and the forearm is difficult to control. It depends on the contact pressure. We carried out a lot of experiments before obtaining an appropriate protocol. Nevertheless improvements need to be considered, such as finding a way to immobilize the arm during the recording of the image, without disturbing the physiological behavior.

Next, we performed experimental measurements with subjects of different gender. In all cases, the results clearly shown the influence of heat transport in human tissue. Results between male and female subjects are relatively close.

Finally, this database could serve to improve and validate numerical models of human skin.

\section{References}

1. K. Khanafer and K. Vafai. Synthesis of mathematical models representing bioheat transport. Advance in Numerical Heat Transfer, W.J. Minkowycz, E. M . Sparrow , and J . P . Abraham CRC Press, Vol. 3:1-28, 2009.

2. E.M. De Boer and D.P. Bruynzeel. Patch tests : Evaluation by instrumental methods. 
Clinics in Dermatology, 31:203-222, 1996.

3. D. Bauer, R. Grebe, and A. Ehrlacher. A new method to model change in cutaneous blood flow due to mechanical skin irritation: Part ii: Parameter identification procedure. Journal of Theoretical Biology, Volume 238, Issue 3, 7:588-596, 2006.

4. Markus Stucker, Christina Huntermann, Falk Georges Bechara, Klaus Hoffmann, and Peter Altmeyer. Capillary blood cell velocity in periulcerous regions of the lower leg measured by laser doppler anemometry. Skin Research and Technology, 10(3):174-177, 2004 .

5. E. Stikbakke and J.B. Mercer. An infrared thermographic and laser doppler flowmetric investigation of skin perfusion in the forearm and finger tip following a short period of vasculart stasis. Thermology International, 18:107-111, 2008.

6. C. Boué, F. Cassagne, C. Massoud, and D. Fournier. Thermal imaging of a vein of the forearm: Analysis and thermal modelling. Infrared Physics $\&$ Technology, Volume 51, Issue 1:13-20, 2007.

7. H.M. Schnell and J.G. Zaspel. Cooling extensive burns: Sprayed coolants can improve initial cooling management: A thermography-based study. Burns, Volume 34, Issue 4:505-508, 2008.

8. J. George, A. Bensafi, A. M. Schmitt, D. Black, S. Dahan, F. Loche, and J. M. Lagarde. Validation of a non-contact technique for local skin temperature measurements. Skin Research and Technology, 14(4):381-384, 2008. 
9. Claudio Castillo-Martinez, Rodrigo Valdes-Rodriguez, Eleazar S. Kolosovas-Machuca, Benjamin Moncada, and Francisco J. Gonzalez. Use of digital infrared imaging in the assessment of childhood psoriasis. Skin Research and Technology, pages n/a-n/a, 2012.

10. D. Ratovoson, V. Huon, V. Costalat, and F. Jourdan. Combined model of human skin - heat transfer in the vein and tissue: experimental and numerical study. J. of QIRT, $8(2): 165-186,2011$.

11. F.J. Wyllie and A.B. Sutherland. Measurement of surface temperature as an aid to the diagnosis of burn depth. Burns, 17(2):123 - 127, 1991.

12. M.E.J. Hackett. The use of thermography in the assessment of depth of burn and blood supply of flaps, with preliminary reports on its use in dupuytren's contracture and treatment of varicose ulcers. British Journal of Plastic Surgery, 27(4):311 - 317, 1974.

13. B.R. Mason, A.J. Graff, and S.P. Pegg. Colour thermography in the diagnosis of the depth of burn injury. Burns, 7(3):197 - 202, 1981.

14. N. Bouzida, A. Bendada, and X. P. Maldague. Visualization of body thermoregulation by infrared imaging. Journal of Thermal Biology, 34:120-126, 2009.

15. A. Chrysochoos, V. Huon, F. Jourdan, J.-M. Muracciole, R. Peyroux, and B. Wattrisse. Use of full-field digital image correlation and infrared thermography measurements for the thermomechanical analysis of material behaviour. Strain, Volume 46, Issue 1:117-130, 2010. 
16. H. Pron and C. Bissieux. Focal plane array infrared cameras as research tools. J. of QIRT, 1(2):229 - 240, 2004.

17. V. Honorat, S. Moreau, Jean Michel Muracciole, Bertrand Wattrisse, and Andre Chrysochoos. Calorimetric analysis of polymer behaviour using a pixel calibration of an irfpa camera. Quantitative Infra Red Thermography Journal, 2(2):153-172, 2005.

18. D. Ratovoson. Propriétés thermomécaniques de la peau et de son environnement direct. $\mathrm{PhD}$ thesis, University Montpellier 2, 2011. 


\section{A Comparative study between the different forearm po- sitions on female subject}

We also made all previous measurements with a female subject 30 years old. As the male subject, we selected seven check points on the thermal image of the forearm. We present first, a comparison of results between the horizontal position and and the upward vertical position with cooled and heated bars. We also noted the return to thermal balance was slower in the upwards vertical position (see Figure 11).

Figure 12 shows the comparison of results between the horizontal and the downward vertical position with cooled and heated bars. Note that the return to thermal balance in the horizontal position was a bit faster.

Figure 13 shows the comparison of results between the upward and downward vertical positions with cooled and heated bars. As for the male subject, the return to thermal balance is faster in the downward vertical position.

\section{B Comparative study between cooling and warming on female subject}

Figure 14 shows a comparison between cooling and warming in the horizontal position for the female subject. Except check point 4, results confirm the symmetry of the thermal behavior. 

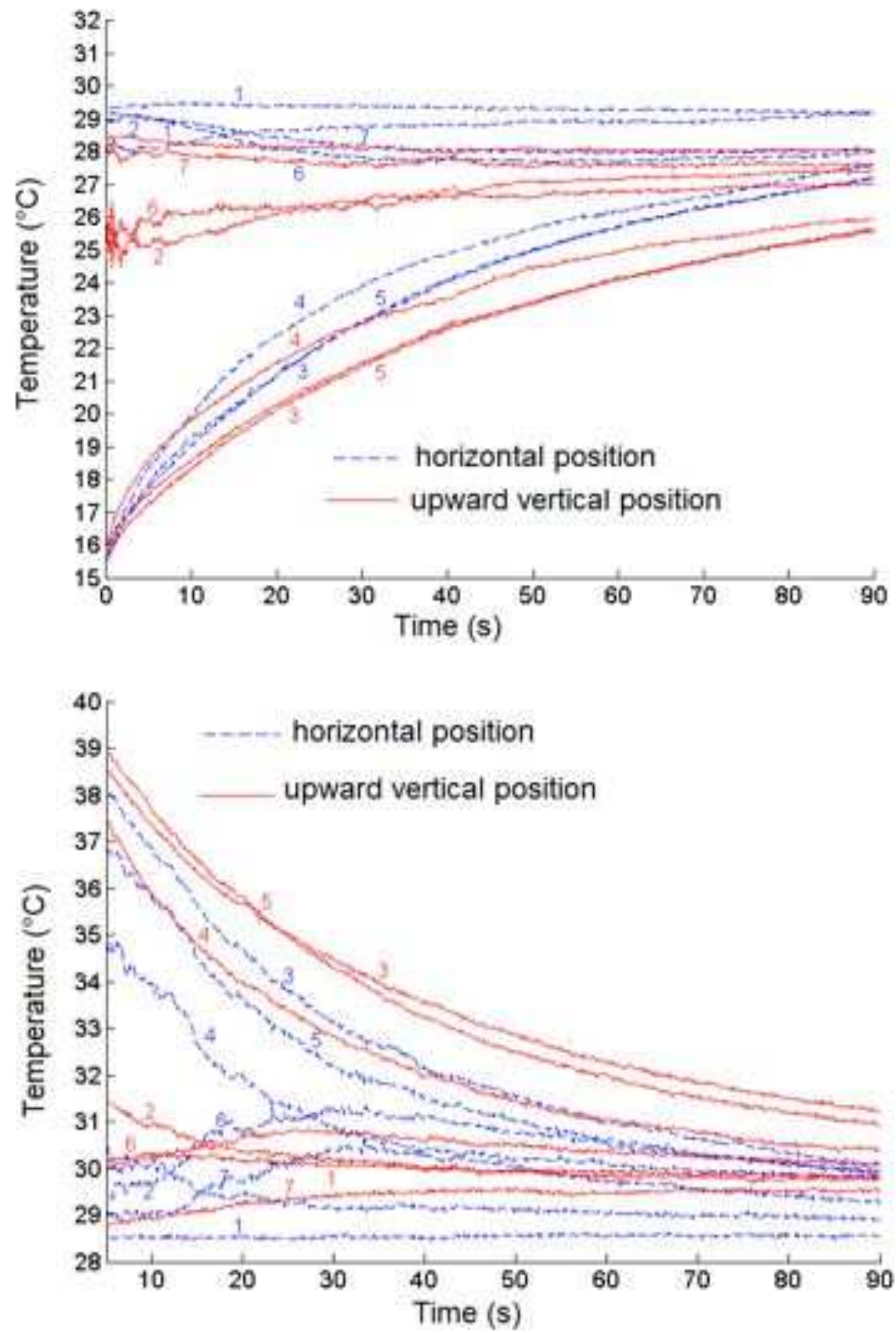

Figure 11: Comparison of experimental results between horizontal and upward vertical positions: female subject - cooled bar (top) and heated bar (bottom) 

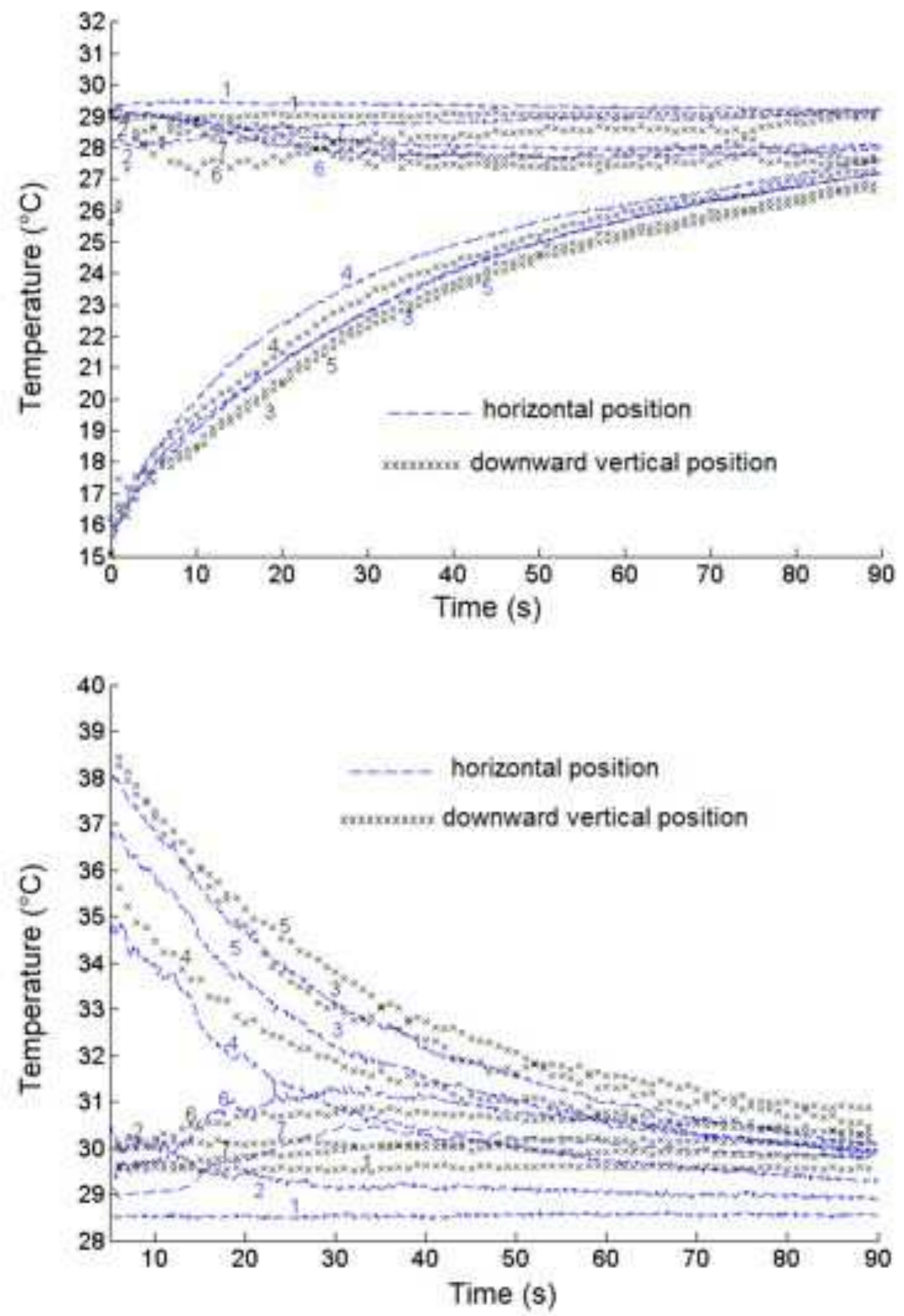

Figure 12: Comparison of experimental results between horizontal and downward vertical positions: female subject - cooled bar (top) and heated bar (bottom) 

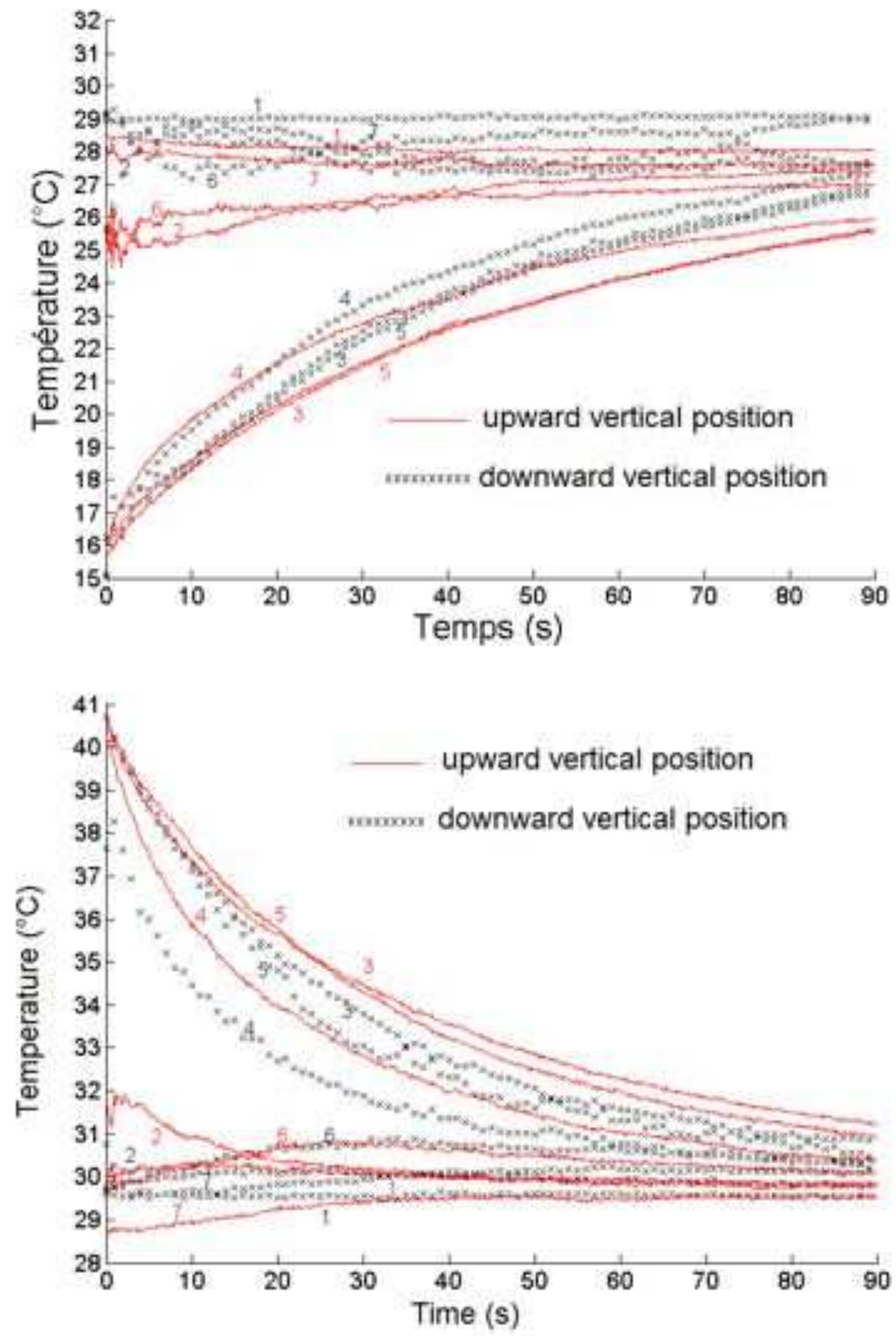

Figure 13: Comparison of experimental results between upward and downward vertical positions: female subject - cooled bar (top) and heated bar (bottom) 


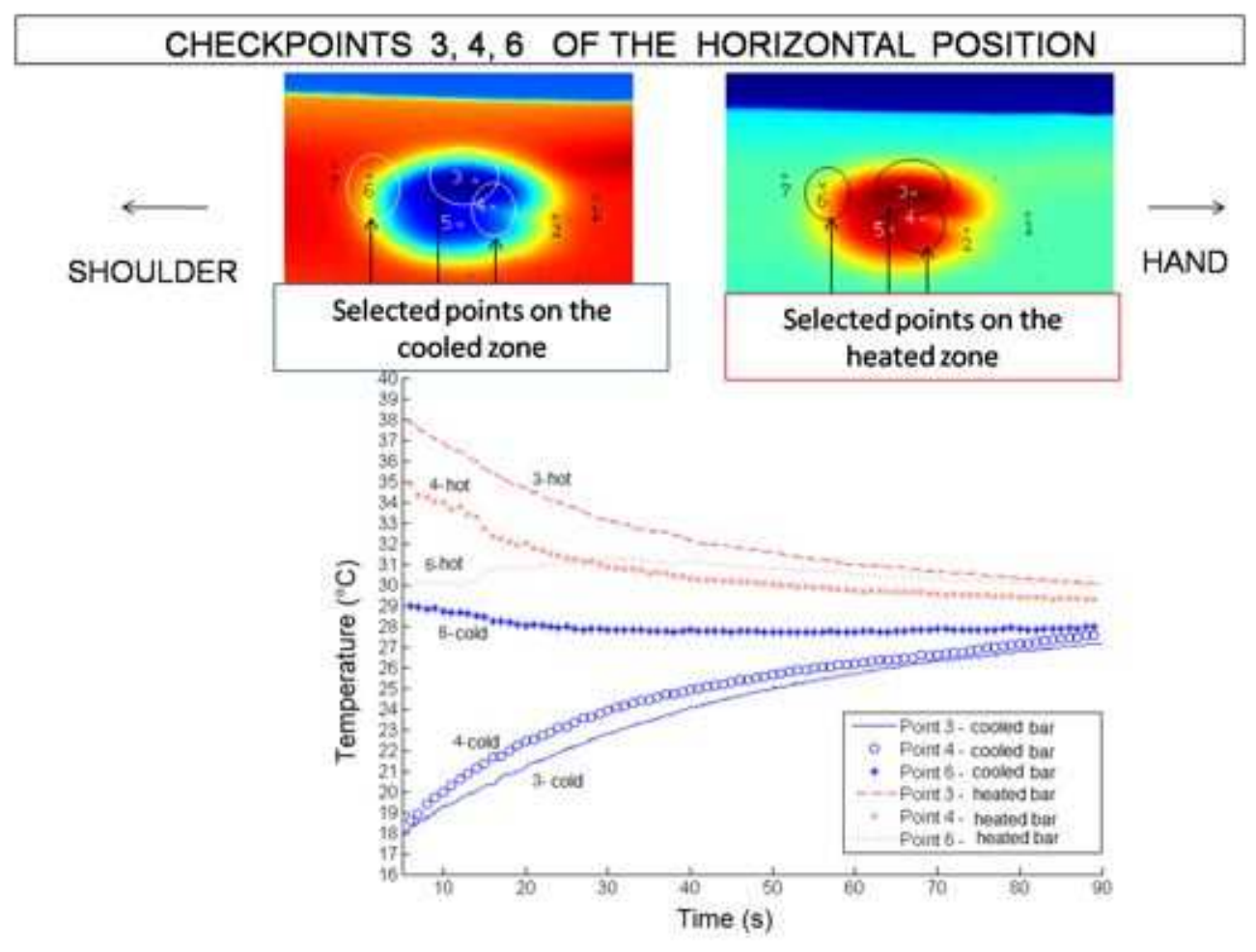

Figure 14: Comparisons between cooling and warming in the horizontal position for check points 3, 4 and 6: female subject

Figure 15 shows a comparison between cooling and warming in the upward vertical position and figure 16 shows a comparison in the downward vertical position. These results also confirm the symmetry of the thermal behavior. 


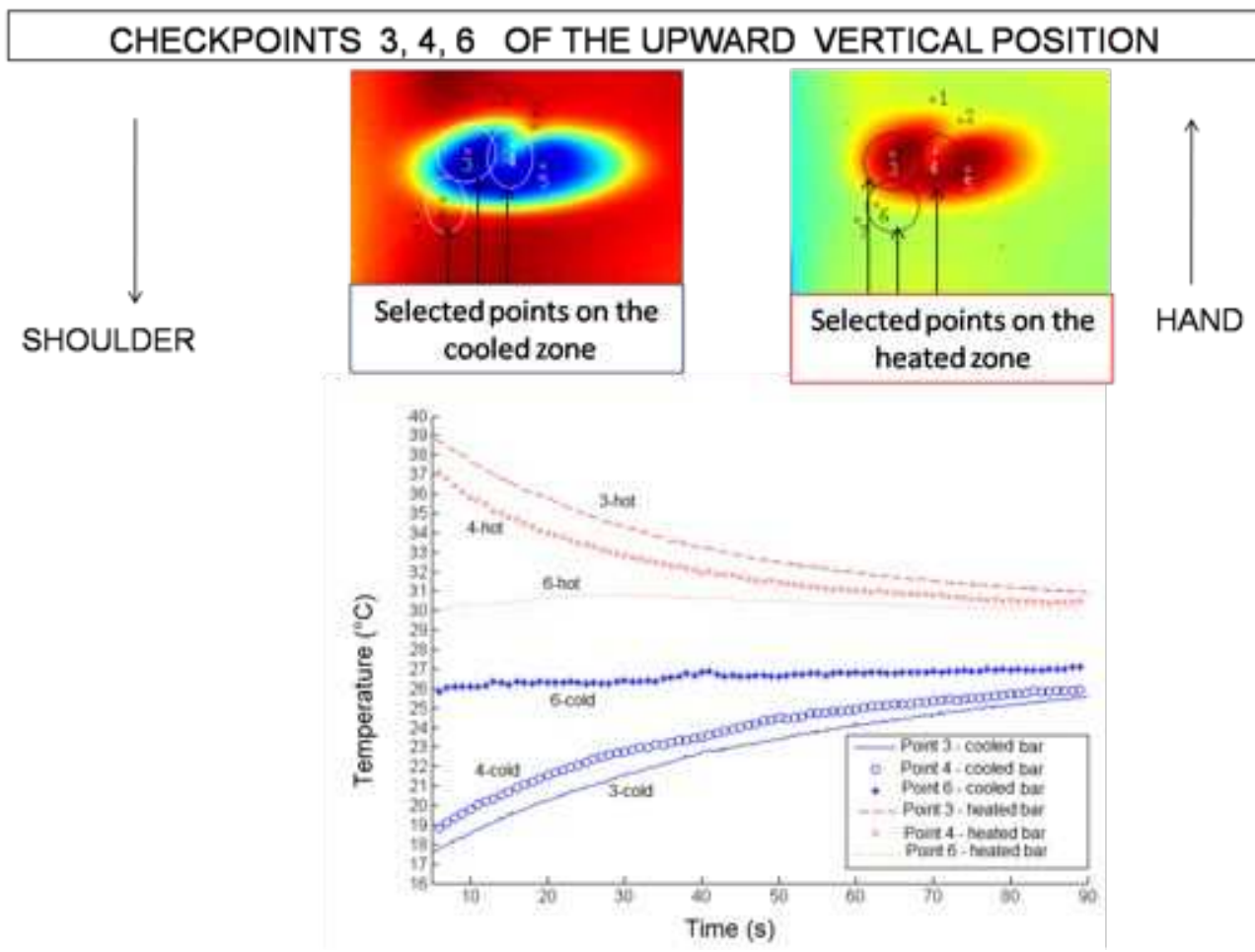

Figure 15: Comparisons between cooling and warming in the upward vertical position for check points 3, 4 and 6: female subject 


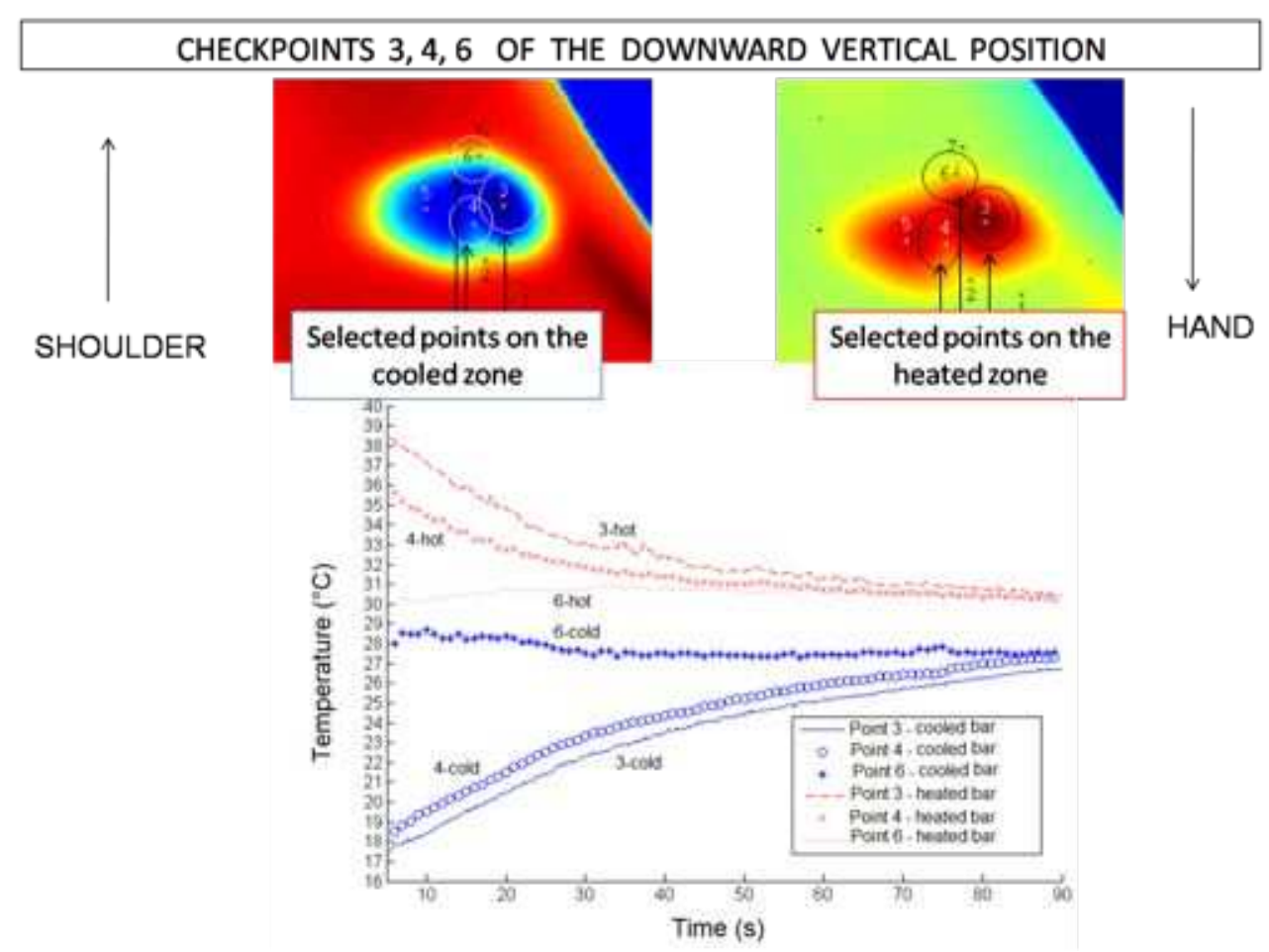

Figure 16: Comparisons between cooling and warming in the downward vertical position for check points 3, 4 and 6: female subject 